\title{
SHIVASWARODAY AN ANCIENT INDIAN SCIENCE: A STUDY OF NASAL OR NOSTRIL CYCLES AND ITS APPLICATIONS
}

\section{D MARATHE ${ }^{1} \&$ JAGDISH ACHARYA ${ }^{2}$}

${ }^{1}$ Research Scholar, Satish Pradhan Dnyanasadhana College, Thane 400604, Maharashtra, India

${ }^{2}$ Research Scholar, Sadguru Academy, At and Post Panchwad, Taluka Wai, Dist. Satara, Maharashtra, India

\begin{abstract}
Shivaswaroday Shastra also known as Nadi Shastra is an ancient Indian science that deals with the power of breath that correlates the breath with Sun, Moon and Five elements viz Space (Aakash), air (vayu), Fire (Agni), Water (Aap) and Earth (Prithvi) mentioned in Indian Yogic science. We inhale and exhale involuntarily and the process is governed by the autonomous nervous system. In our bodies, the right and left nostril do not function simultaneously. When consciously observed, it is noticed that the nasal/nostril cycle has a rhythm of congestion and decongestion with a quasiperiodic of 60 to 90 minutes duration. It means that if you observe your breath then you will notice that at a given time, any one nostril is more dominant and the other one relatively congested. This cycle of congestion and decongestion alternates and keeps changing every couple of hours. Also, during the transition period of this cycle, both nostrils may equally be dominant for a few minutes. In this article, we are trying to introduce the basics of this Nasal cycle and understanding its role in our life.

KEYWORDS: Nadi, Ida, Pingala, Sushumna, Autonomic Nervous System
\end{abstract}

Received: May 25, 2020; Accepted: Jun 15, 2020; Published: Jun 26, 2020; Paper Id.: IJMPERDJUN202099

\section{INTRODUCTION}

The original manuscript of Shiva Swarodaya contains 395 sutras, many of which deal with Health, Wealth \& Happiness and are a dialogue between Lord Shiva and his spouse Goddess Parvati. She seeks knowledge about nature and the governing forces of the universe, in response to which Lord Shiva discloses this precious knowledge of Swara yoga. This knowledge was a closely guarded secret and was available to a select few over the centuries and was transmitted from generation to generation, orally.

Without going to the story of Shiva and Parvati conversation, let us see the science of breathing that evolves from it. The word Shivaswaroday is combination of 'Swara' means sonorous sound produced by airflow through the nostril and 'udaya' means functioning state. 'Shastra' means science. When you observe your breathing then you will observe that air flow in both the nostrils is unequal many of the times and it alternates after some time (generally about 90 minutes). You may observe that at times your left nostril air flow is more than the right side or vice versa. You may also observe that one of the nostrils is completely choked or congested and the other is fully functional. According to Shiva Swaroday Shastra also known as Swarodaya Vijnan (abbreviation SSS will be used) left and right-side nostrils are called Chandra (Ida) Nadi and Surya (Pingala) Nadi respectively. Nadi can be referred to as Channel. When right nostril is fully functional (full airflow; decongestion) it is said that Surya Nadi is active (Parasympathetic Activation) and when left nostril is fully functional it is said that Chandra Nadi (Ida Nadi) is active (Sympathetic Activation). This can be determined by holding your palm horizontally below the nostrils 
and try to exhale heavily on the palm. Then you can easily make out which nostril air flow is dominant.

You may also observe sometimes that the airflow in both of your nostrils is almost equal. This state is called Sushumna or Sushumna Nadi.

\section{IDA, PINGALA AND SUSHUMNA}

Nostril rhythm changes from person to person. It depends upon atmospheric conditions, daily routine, regular food intake etc. Prolong unilateral breathing can be due to disorder in the body such as migraine, cough and cold, fever, asthma etc. In our discussion we will consider normal person who doesn't have cough and cold, fever and living normal routine.

\section{Ida Nadi (Chandra Nadi)}

It is the state of breathing when the left nostril is fully active. According to SSS, Ida Nadi is related to the moon (known as Chandra) and when it is fully active has cooling effect on the body (moon is sheetal means its light has a cooling effect). It can be further related to functions of the right brain. It means that for the duration for which the Ida Nadi is active, one can show greater capacity to imagine, memorise, judgement, important decisions which are essentially right brain functions. The tasks which require a peaceful and steady mental concentration can be completed with the desired satisfaction for the duration of this Nadi.

\section{Pingala Nadi (Surya Nadi)}

It is the state of breathing when the right nostril is fully active. This is related to the Sun (Surya) which is a ball of fire (agni). When Surya Nadi is active, according to SSS, our body gets warm or heated and during this time physical activities like exercise, vigorous work, heated discussions, arguments, conspiracy etc are usually seen to be effectively done. This state activates the left brain, and related functions can be accomplished effectively.

\section{Sushumna Nadi}

It is the state when airflow in both the nostrils is almost even or equal. This period when Sushumna is active, it is considered to be advisable to do activities which do not require maximum mental or physical efforts. It is the observation of many that this is the best time for meditation where there is no consideration of material gain.

\section{BREATH AND FIVE ELEMENTS}

Five elements in yoga are Earth (prithvi), Fire (agni), water (Aap), Air (vayu) and Space (Akash). There are general moods and physical processes associated with each element.

Earth: Grounding, calming; keeps ego in check, the energy of bones, muscles, tissues, etc

Water: Provides the ability to adapt, flow, act selflessly, and avoid unhealthy attachments, helps in homeostasis of blood, other bodily fluids etc.

Fire: Brings confidence and courage; the energy of metabolism, drive, and creativity, an excess can present as anger or hatred.

Air: A channel for clear communication and self-expression; influences your ability to act from a place of compassion and love; jealousy occurs when out of balance 
Space: A container for all the other elements; the source of intuition and wisdom from the universe; associated with magnanimity and expansion

An average healthy person free from any cough and cold, fever, asthma and other infections which can affect breathing, breathes 15 times in minute, 900 times in an hour or 21600 times per day. Each element, according to SSS predominates periodically in the body for a specific period as mentioned below, influencing the flow of our thoughts and moods.

- For about 20 minutes (300 breaths) the Earth element dominates.

- For about 16 minutes (240 breaths) the Water element dominates.

- For about 12 minutes (180 breaths) the Fire element dominates.

- For about 8 minutes (120 breaths) the Air element dominates.

- $\quad$ For about 4 minutes (60 breaths) the Akasha element dominates.

One way of becoming aware of the predominance of a particular element is to watch the flow of the breath through the nostrils. The relation between the region of the nostril where airflow is functional predominantly and the respective element is stated below.

- Center of the nostril - Earth element

- Lower part of the nostril - Water element

- Top of the nostril - Fire element

- Obliquely or through the side of the nostril - Air element

- $\quad$ Rotating in the nostril - Akasha or Ether element

\section{AUTONOMIC NERVOUS SYSTEM, SYMPATHETIC AND PARASYMPATHETIC EFFECTS}

Modern physiology texts describe Autonomic nervous system and analyse the sympathetic and parasympathetic effects of various organs and systems of the human body. If you correlate this with SSS then you will find that ancient Indian life science was far ahead of its time.

The autonomic nervous system serves as the relay between the Central Nervous System (CNS) and the internal organs. It controls the lungs, the heart, smooth muscle, and exocrine and endocrine glands. The autonomic nervous system controls these organs largely without conscious control; it can continuously monitor the conditions of these different systems and implement changes as needed. The autonomic nervous system comprises of Sympathetic and Parasympathetic nervous system

The sympathetic nervous system is responsible for the immediate response that occurs when one encounters a dangerous situation. Examples of functions controlled by the sympathetic nervous system include an accelerated heart rate and inhibited digestion. These functions help prepare an organism's body for the physical strain required to escape a potentially dangerous situation. In such situations it dilates pupils, bronchi, inhibits salvation, digestion and contraction of bladder, increases heart rate. 
The parasympathetic nervous system allows one to rest and digest. The parasympathetic system's functions conserve energy: slowing down the heart rate, reducing contractile forces of both cardiac and gastrointestinal muscle. It does exactly opposite of sympathetic nervous system. It stimulates salvation, digestion, bile secretion, causes bladder to contract, constricts bronchi and pupils.

We all know that the modern medical fact that left hemisphere of the brain controls the right side of the body and vice versa. Therefore by the knowledge of SSS we can effectively perform functions of the right brain when left nostril (Ida/ Chandra Nadi) is active and functions of the left brain when right nostril (Surya / Pingala Nadi) is active.

\section{OBSERVATIONS, RESULTS AND DISCUSSION:}

Consciously observing the breath one can follow the things mentioned below and note the readings to come to the inference about the energy flow in the body, ease in the routine work, time when the decisions are taken, trading, eating, digestion, sound sleep etc

These are as follows.

- Waking up in the morning when Chandra Nadi is active and step out of the bed with left leg first. Due to sympathetic stimulus, pupils are dilated, lungs are dilated for more oxygen, feeling fresh.

- Go to bed at night when Surya Nadi is active, because due to parasympathetic stimulation heart beats slow down, rate of respiration slows down, pupils get constricted which facilitates closing of eye lids and further person falls asleep quickly and naturally.

- One can corelate that during active Chandra Nadi, sympathetic stimulation and during Surya Nadi, parasympathetic stimulation as per modern physiology.

- Take a Bath when Surya Nadi is active

- Consume food when Surya Nadi is active

- Reading can be performed effectively when Chandra Nadi is active. and similarly, creative writing, when Surya Nadi is active.

- Massaging of the body is found to be extremely beneficial when received during active Chandra Nadi and also if the Surya Nadi of the masseuse.

- Riding vehicle during Surya Nadi.Step out of the house for your duty or business with the foot corresponding to the active Nadi. If left nostril (Chandra Nadi) is active, then step out with left foot first and if Surya Nadi is active then step out with right foot.

- During Sushumna that is when both the nostrils air flow is almost equal, better to avoid where there might be exchange of words, good time for meditation, spiritual activities.

One must remember and consult doctor for prolonged unilateral nostril breathing. Because it might be as a result of complete or partial nasal obstruction and may be correlated with a number of chronic disorders such as migraine, hyperthyroidism, asthma, peptic ulcer, dysmenorrhoea, lack of libido, cardiac symptoms, fever, inadequate oral intake and electrolyte imbalance. Breathing exclusively through one nostril may alter the autonomic functions well. 
There are ways and means by which active Nadi can be altered.

\section{CONCLUSIONS}

When Chandra Nadi is functioning, the right hemisphere of the brain is active and when Surya Nadi is functioning, the left hemisphere of the brain is active. A few significant functions of the right brain are in imagining, memorising, emotional, contemplating, fantasy based, presenting possibilities, impetuous, risk taking. The left brain is logical, practical, mathematical, physical activities, critical. If one consciously reads one's breathing pattern and takes up those activities related to the right and the left brain owing to the respective Nadi, then the success and the satisfaction of work will be phenomenal. Over all one can say Chandra Nadi is mentally active and Surya Nadi is physical active. It is beneficial to carry out creative activities during active Chandra Nadi and physical action during active Surya Nadi. The effect of conscious breathing on emotion and energy flow can be studied using the data of breathing pattern as regards the three Nadis mentioned in the paper of the people whose routine is normally regular.

\section{REFERENCES}

1. Muktibodhananda, S. (1999). Swara Yoga. Munger, Bihar, India: Bihar School of Yoga.

2. Swami Rama. Pranayama: The Royal Path: Practical lessons on Yoga. The Himalayan Institute Press Honesdale, Pennsylvania, 1979; 55-70.

3. Ahmed, Shaymaa J., Nawfal K. Yas, and Hatem A. Hatem."Dna Polymorphism of Interleukin Il-4 of Nasal Mucosal Stem Cells in Nasal Polyps of Iraqi Patients." International Journal of Bio-Technology and Research (IJBTR) 7. 3, Jun 2017, 11-16

4. Breath, Mind and Consciousness by Harish Johari, p. 52-3

5. Cardiac symptoms and nasal obstruction By Cvetnic S, Cvetnic V. Rhinology 1980; 18: 47-50.

6. Fairbanks DNF. Complications of nasal packing. Otolaryngol Head Neck Surg 1986; 94: 412-415.

7. KADAM, PRIYANKA, et al. "Use of Heart Rate Variability for the Detection of the Depth of Anesthesia. "International Journal of Electronics, Communication \& Instrumentation Engineering Research and Development (IJECIERD) 4. 3, Jun 2014, 27-32

8. $\quad$ Refining the breath by Doug Keller 2007

9. The Effects of Right and Left Nostril Breathing on Cardiorespiratory and Autonomic Parameters by Nidhi Jain, R.D. Srivastava* and Anil Singhal**

10. Indian J Physiol Pharmacol 2005; 49 (4) : 469-474

11. Aljamali, Nagham Mahmood. "Survey On."TJPRC: International Journal of Pharmacological and Toxicological Research (TJPRC: IJPTR). 1. 1, Jun 2015, 1-8

12. A scientific Analysis of Nasal Cycle and its Applications By Yogacharya Dr Ananda BalyogiBhavanani International Cente for Yoga education and Research, Pondicherry

13. Mali, Arvind., VijayaLaximi. Pandit, and D. E. V. I. P. R. I. Y. A. Majumder. "Biosorption of heavy metals by dead fungal biomass." IJCSEIERD 4.3 (2014): 11-20.

14. Effects of a Conscious Breathing Intervention on Emotion and Energy Flow

15. Research Paper, Holistic Studies by Amy Heath, Heather Mashuga, Ann Arens St. Catherine University

16. Swara Chintamani: Divination by Breath, translated by S. Kannan, Kannan Publications 

